This item was submitted to Loughborough's Research Repository by the author.

Items in Figshare are protected by copyright, with all rights reserved, unless otherwise indicated.

\title{
Threshold cointegration and the short-run dynamics of twin deficit hypothesis in African countries
}

PLEASE CITE THE PUBLISHED VERSION

http://dx.doi.org/10.1016/j.jeca.2015.03.001

\section{PUBLISHER}

(C) Elsevier

VERSION

AM (Accepted Manuscript)

\section{PUBLISHER STATEMENT}

This work is made available according to the conditions of the Creative Commons Attribution-NonCommercialNoDerivatives 4.0 International (CC BY-NC-ND 4.0) licence. Full details of this licence are available at: https://creativecommons.org/licenses/by-nc-nd/4.0/

\section{LICENCE}

CC BY-NC-ND 4.0

\section{REPOSITORY RECORD}

Ahmad, A.H., Olalekan B. Aworinde, and Christopher Martin. 2019. "Threshold Cointegration and the Short-run Dynamics of Twin Deficit Hypothesis in African Countries". figshare. https://hdl.handle.net/2134/17966. 


\title{
Threshold Cointegration and the Short-run Dynamics of Twin Deficit Hypothesis in African countries
}

\author{
Ahmad Hassan Ahmad*† Olalekan Bashir Aworinde ${ }^{\ddagger}$ \\ Christopher Martin ${ }^{\S}$
}

\begin{abstract}
This paper examines the relationship between the fiscal deficit and the current account deficit using the threshold cointegration approach of Hansen and Seo (2002). Using quarterly data for nine African countries for the period 1980-2009, a long-run positive cointegrating relationship is established for six out of the nine countries examined, while the relationship is negative for the other three. This provides qualified support for the twin convergence hypothesis. Threshold error correction effects show some diversity in the speed of adjustment of the current account relative to the speed of adjustment of the fiscal deficit. This may be a reflection of differences in the way fiscal policy issues are handled across the countries.
\end{abstract}

Key Words: Fiscal deficits, Current account deficits, Threshold cointegration, African countries.

JEL Classification: H60, H62, C22,

${ }^{*}$ We are grateful to the editor and acknowledge the useful and constructive comments received from two anonymous referees.

${ }^{\dagger}$ School of Business \& Economics, Loughborough University, Leicestershire, LE11 3TU, United Kingdom. A.H.Ahmad@lboro.ac.uk

${ }^{\ddagger}$ Department of Economics, University of Bath, Bath, BA2 7YA, United Kingdom \& Tai Solarin University of Education, Nigeria

$\S$ Department of Economics, University of Bath, Bath, BA2 7YA, United Kingdom 


\section{Introduction}

Persistent fiscal and current account deficits are a major policy concern, irrespective of whether the country affected is developed or developing. This is because large fiscal deficits may lead to crowding-out of private investment if they cause interest rates to rise. Similarly, a large current account deficit could lead to a decline in competitiveness, a transfer of wealth to foreign nationals and a depletion of foreign exchange reserves, possibly triggering a currency crisis. From the traditional open-economy macroeconomic perspective, there are three main reasons to expect a positive relationship between the fiscal deficit and the current acount deficit, the "Twin Deficit" hypothesis. First, an increase in the fiscal deficit may induce an increase in the interest rate that causes capital inflows and an appreciation of the exchange rate, with unfavourable effects on the current account. Second, an increase in the fiscal deficit may lead to an increase in the demand for imports, causing a worsening of the current account. And third, a worsening of the current account deficit will reduce tax revenue and thus increase the fiscal deficit. In contrast to the traditional Keynesian view, the Ricardian equivalence hypothesis of Barro $(1974,1989)$ argues that the fiscal deficits and the current account deficits are unrelated. Kim and Roubini (2008) argue for a negative relationship, a "Twin Divergence" hypothesis.

Existing empirical evidence on the twin convergence hypothesis is mixed. Early work, based on simple single equation models, includes Milne (1977), Bernheim (1987), Bryant et. al (1988) and Ziets and Pemberton (1990). These authors report a positive relationship between the two deficits, supporting the hypothesis. More recent studies often use vector autoregressive (VAR) models. Abell (1990), Bechman (1992) and Rosensweig and Tallman (1993) support the hypothesis. However Enders and Lee (1990) find no significant association between the deficits. Kim and Roubini (2008), Corsetti and Muller (2006) and Muller (2008) report a negative relationship.

Another strand of the literature examines the cointegrating relationship between the current account deficit and the fiscal deficit that is implied by the twin convergence hypothesis. Bechman (1992) and Dibooglu (1997) were able to detect such a cointegrating relationship. However more recent evidence is less supportive. For example, Holmes et. al (2010a) and Holmes et. al (2010b) find that the fiscal deficit is stationary in a sample of the EU countries when allowance is made for crosssectional dependence and structural breaks and that the current account deficits of these countries are sustainable in the long-run. Grier and Ye (2009) also stress the importance of accounting for structural breaks; they find no long-run relationship between the fiscal deficit and the current account balance when this is done.

The objective of this paper is to investigate the possibility of a long-run but non- 
linear relationship between the fiscal deficit and current account deficit in a sample of African countries, where we model nonlinearity within the context of threshold cointegration. Previous studies have neglected this issue by assuming symmetric adjustment: the failure to reject the null of no cointegration in some of these studies could be attributed to the neglect of threshold effects (Holmes, 2011). Pragidis et. al (2015) have found that adjustments to fiscal shocks could be asymmetric. A notable exception is Holmes and Panagiotidis (2009) who used a flexible technique to look into the asymmetric adjustments of the US current account and found that adjustment to equilibrium was mainly driven by the US exports.

In contrast to all of the previous work cited above, apart from Holmes and Pangiotidid (2009), this study considers the possibility of a long-run relationship between the twin deficits that is characterised by threshold cointegration. There is a strong rationale for considering these effects. The relationships between the fiscal deficit and the interest rate and between the interest rate and the exchange rate may be nonlinear, so the impact of a given fiscal expansion may differ according to the size of the deficit; in particular, the impact may be larger if the deficit exceeds a critical threshold level. This implies a different relationship between the twin deficits depending on whether the fiscal deficit exceeds this threshold. More generally, financial markets in most African countries are imperfect and underdeveloped. Adjustment in such environment may well be irregular and ad hoc, implying a non-linear relationship between the two series. To investigate these non-linearities and asymmetric adjustments between these deficits, this paper employs the Hansen and Seo (2002) threshold cointegration methodology, where the short-run dynamics reflect two regimes, which reflect deviations from the long-run relationship between the current account balance and the fiscal deficit, relative to a threshold. This approach allows for asymmetric adjustment dynamics between the series.

Another contribution of the paper is that it is investigating relationship between the fiscal deficit and the current account deficit for a sample of African countries, which have been largely overlooked by the previous studies. This is important as the countries in the sample have experienced both fiscal and current account deficits during the sample period, except Botswana, which has enjoyed relatively favourable current account balance for most of the sample period until the recent financial crisis. Therefore, establishing dynamic relationship between these deficits will shed more light on the appropriate policy measures needed to be adopted.

The rest of the paper is structured as follows. Section 2 outlines the methodology of the Hansen and Seo (2002) bi-variate threshold approach used in this analysis. Section 3 discusses the sources and the definitions of the data. Section 4 outlines our estimation strategy and discusses our empirical results. Section 5 concludes. 


\section{Methodology}

In order to test the validity of the twin deficits hypothesis within the context of cointegration theory, the empirical literature has typically used a linear model that takes the following form:

$$
C A B_{t}=\alpha+\beta F D_{t}+\varepsilon_{t}
$$

where $C A B$ is the current account, $F D$ is the fiscal deficit and $\varepsilon$ is an error term. This relationship can be embedded in the following linear VECM model of order $l$ :

$$
\left(\begin{array}{c}
\Delta C A B_{t} \\
\Delta F D_{t}
\end{array}\right)=\mu+\alpha \omega_{t-1}+\Gamma(L)\left(\begin{array}{c}
\Delta C A B_{t-1} \\
\Delta F D_{t-1}
\end{array}\right)+\varepsilon_{t}
$$

where $\omega_{t-1}=C A B_{t-1}-\beta F D_{t-1}$ defines the long-run relationship and $\Gamma(L)=\Gamma_{1}+$ $\Gamma_{2} L+. .+\Gamma_{l} L^{l-1}$ is a matrix polynominal is the lag operator, $L$. This model implies a constant speed of adjustment towards the long-run equilibrium. Hansen and Seo (2002) relaxed this assumption using a two-regime threshold non-linear VECM:

$$
\Delta x_{t}=\left\{\begin{array}{lll}
A_{1}^{\prime} X_{t-1}(\beta)+u_{t} & \text { if } & \omega_{t-1}(\beta) \leq \gamma \\
A_{2}^{\prime} X_{t-1}(\beta)+u_{t} & \text { if } & \omega_{t-1}(\beta)>\gamma
\end{array}\right\}
$$

with

$$
X_{t-1}(\beta)=\left(\begin{array}{c}
1 \\
\omega_{t-1}(\beta) \\
\Delta x_{t-1} \\
\Delta x_{t-2} \\
\cdot \\
\cdot \\
\Delta x_{t-l}
\end{array}\right)
$$

where $x_{t}$ is a $p$-dimensional $I(1)$ time series (in our case, $p=2$ ) which is cointegrated with a unique $p \times 1$ cointegrating vector $\beta$, and $\omega_{t}(\beta)=\beta^{\prime} x_{t}$ is the $I(0)$ errorcorrection term. $u_{t}$ is an error term, $A_{1}$ and $A_{2}$ are coefficient matrices, and $\gamma$ denotes the threshold parameter. The threshold model in equation (3) has two regimes, depending on whether deviations from the equilibrium (defined by the value of the error-correction term) are below or above the threshold, $\gamma \cdot A_{1}$ and $A_{2}$ describe the dynamics in each of the regimes. It is possible that the relationship is cointegrated in only one regime, implying that there is no inherent tendancy for the variables $x_{t}$ to move towards equilibrium in the other regime (indicated by a zero entry in the second row of the relevant $A$ vector). 
Hansen and Seo (2002) proposed two heteroscedastic-consistent $L M$ test statistics for the null hypothesis of linear cointegration (i.e., there is no threshold effect), against the alternative of threshold cointegration. The first test is used when the true cointegrating vector is known apriori, and is denoted as:

$$
\operatorname{SupLM}=\underset{\gamma L \leq \gamma \leq \gamma U}{\operatorname{SupL} M}(\beta, \gamma)
$$

where $\beta_{0}$ is the known value of $\beta$ (in the case analyzed below, $\beta_{0}=1$ ). The second test is used when the true cointegrating vector is unknown and is represented as:

$$
\operatorname{SupLM}=\underset{\gamma L \leq \gamma \leq \gamma U}{\operatorname{Sup} L M}(\tilde{\beta}, \gamma)
$$

where $\tilde{\beta}$ is the estimate of $\beta$ under the null hypothesis $\{$ is that correct?\}. In both equations (5) and (6), $\left[\gamma_{L}, \gamma_{U}\right]$ is the search region, set so that $\gamma L$ is the $\pi_{0}^{t h}$ percentile of $\tilde{\omega}_{t-1}$ and $\gamma U$ is the $\left(1-\pi_{0}^{t h}\right)$ percentile. Andrews (1993) suggested setting $\pi_{0}$ between 0.05 and 0.15 . Bootstrapping methods are used to calculate the asymptotic critical values and the $p$-values.

\section{$3 \quad$ Data and the Estimated Results}

The data set is obtained from the IMF Government Finance Statistics (GFS) and the Balance of Payment Statistics (BOP) databases as well as the World Bank Development Indicators. For some countries, data is also sourced from the Central Bank. The fiscal deficit $(F D)$ is constructed as the difference between total revenue and the total expenditure expressed as a percentage of the GDP. The current account balance $(C A B)$ is the sum of the balance of trade (exports minus imports of goods and services), net factor income (such as interest and dividends) and net transfer payments (such as foreign aid) expressed as a percentage of the GDP. The data-set is quarterly, covers the period 1980:1 to 2009:4 and contains data for Botswana, Cameroon, Egypt, Ethiopia, Ghana, Kenya, Morocco, Nigeria, South Africa, Tanzania, Tunisia, and Uganda. Figure 1 plots the fiscal deficit and current account balance for each country, where the volatility of these series is apparent.

The results of Augmented Dickey-Fuller (ADF) and Phillips and Perron (PP) tests for stationary are reported in Table 1 . Non-stationarity of either deficit cannot be rejected at $5 \%$ significance level in nine of the twelve countries considered. But at least one of our test statistics indicates that the fiscal deficit is stationary in Ghana and Tunisia while the current account is stationary in South Africa. Since 
threshold cointegration tests are only valid on non-stationary series of the same level of integration, we exclude these countries from the remainder of our analysis.1

To assess the evidence for threshold cointegration, we use the sup $L M$ test where the true cointegrating vector is assumed to be unknown as stated in equation (6). The $p$-values for this test were calculated using a parametric bootstrap computed with 10,000 simulation replications ${ }^{2}$. The results are presented in Table 2. They point to the presence of threshold cointegration for each of the nine countries. However, rejection of linearity is only at $10 \%$ for Egypt, Ethiopia and Morocco. The parameters of the threshold cointegration model in equation (3) are calculated over a $200 \times 200$ grid on both the threshold parameter $(\gamma)$ and the cointegrating vector, $(\hat{\beta})$. The estimated threshold parameter that defines the two regimes in each country are reported in column 4 of Table $2^{3}$. Estimates of $\beta$ are reported in column 5 of Table 2. In an majority of countries, Botswana, Cameroon, Egypt, Morocco, Nigeria and Tanzania, there is a positive threshold cointegrating relationship between the current account deficit and the fiscal deficit. This positive relationship supports the twin deficits hypothesis. In a minority of the countries, Ethiopia, Kenya and Uganda, the estimated relationship is negative, supporting the twin divergence hypothesis proposed by Kim and Roubini (2008).

We next investigate dynamic adjustment, considering the full set of estimated parameters, contained in Tables 3 - 7. Adjustment is asymmetric if the coefficient on the error-correction term differs between regimes. We investigate this by plotting the estimated regression functions of $\triangle C A B_{t}$ and $\triangle F D_{t}$ as a function of the estimated cointegrating relationship, $w_{t-1}$, holding other variables constant. These are reported in Figures 2(a) - 2(i). It is evident from Table 3 and Figure 2(a) that there is a near zero error correction effect on the left hand side of the threshold parameter for both the $F D$ and the $C A B$ equations in Botswana. However, on the right hand side of the threshold parameter, the responses of both variables to the error correction term are statistically significant. Results for Cameroon indicate that the fiscal deficit and the current account balance equations have positive error effects below the estimated

\footnotetext{
${ }^{1}$ We have also undertaken Engle-Granger and Gregory-Hansen Tests of cointegration and accounting for a structural break in the mean of the series. However, the results indicate that there is no evidence of linear cointegration between the current account deficits and the fiscal deficits in these countries. The results are not reported in this paper, but available on request.

${ }^{2}$ The optimum lag length was determined using the information criteria. The Schwarz information criterion suggests 2 lags for the countries, which were used.

${ }^{3}$ The Hansen and Seo (2002) methodology can only define the system into two regimes separated by an estimated threshold. The two regimes imposed on all the countries by the technique is an apparent limitation of this paper. Consequently, this calls for further investigation with an approach that can accommodate more than two regimes.
} 
threshold but a near zero response of both variables above it.

The error-correction effect for Egypt, as plotted in Figure 2(c), shows that the current account balance equations and the fiscal deficit equations have near zero effects on the left side of the threshold, implying persistent divergence between the $F D$ and the $C A B$ (and no response to the error-correction term), whereas on the right side of the threshold, only the current account balance has a negative error correction effect. Therefore, both the $C A B$ and the $F D$ decrease as the error-correction term increases.

Figure 2(d) reports the results for Ethiopia, where it is shown that the current account balance has a strong negative error correction effect on the left side of the threshold and also has a slight decline on the right side. In contrast, the fiscal deficit equation shows strong positive error effects on the left side of the threshold and declines slightly on the right side. Figure 2(e) reports the error-correction effect for Kenya, which shows that the current account balance equation is positive and their is a near zero error-correction and fiscal deficits equations have a strong positive error correction effect on the left side of the threshold. There is a near zero error-correction effect for both equations on the right side of the threshold. In Morocco, there is are asymmetric effects indicated the positive (negative) error correction term for the FD $(\mathrm{CAB})$. There is a near-zero error correction effect for the current account balance equations on the right side of the threshold and the fiscal deficit equations have a slightly positive error correction effect.

In the case of Nigeria and Tanzania, the fiscal deficits equation showed a strong positive error correction effects, while the current account balance equation has a strong negative error correction effect on the left side of the estimated threshold. However, on the right side there is a slight positive error correction effect for both the current account balance and the fiscal deficits equations. Results for Uganda indicate that the current account balance has near zero error correction effects and the fiscal deficit has a strong negative error correction effect on the left side of the threshold, whereas both equations display slight negative effects on the right side of the threshold.

In every country, the estimated thresholds are large, implying substantial persistence of disequilibrium in the system. This may reflect both speficic factors (eg use of revenue from the sale of diamonds in Botswana to finance fiscal deficits or sub-optimal allocation of revenue from crude oil exports in Nigeria) and general factors (eg the impact of commodity price volatility in largely agrarian economies, tax evasion and the effects of a large informal sector, political instability and labor unrest, with consequent negative impacts on capital inflows negatively and a decline in FDI, remittance and aid flows). These factors highlight the importance of structural 
fiscal reforms in these countries as was recommended by Neaime (2015) for some EU countries.

\section{Conclusion}

This paper has examined the twin deficits hypothesis in a sample of African countries using a threshold cointegration technique. The methodology allows for investigating the long-run relationship between the fiscal deficit and current account balances while exploring the existence of a threshold that defines two distinct regimes. This means that cointegration is only obtained within one of the regimes. Hansen and Seo supLM tests rejected the null of linear cointegration in favour of a two-regime threshold cointegration.

We found a positive cointegrating relationship between the current account and the fiscal balances for six of the nine countries considered: Botswana, Cameroon, Egypt, Morocco, Nigeria and Tanzania. These results are consistent with twin deficits hypothesis. A negative cointegrating relationship is found for a minority of countries: Ethiopia, Kenya and Uganda, consistent with the twin divergence hypothesis proposed by Kim and Roubini (2008). On balance, these results provide qualified support for the twin convergenc hypothesis.

Estimated error correction effects reveal a complex pattern of dynamic adjustment. In some cases (e.g. Botswana, Kenya and Uganda), the current account adjustst faster than the fiscal deficit. In others (e.g. Cameroon and Egypt), we find the opposite is the case, adjustments are higher in the fiscal deficits. These differences reflect marked differences in the way fiscal issues are dealt with across the countries. 


\section{References}

[1] Abell, J. D. (1990). "The Role of the Budget Deficit during the Rise in the Dollar Exchange Rate from 1979-1985", Southern Economic Journal 57(1), 66-74.

[2] Andrews, D. (1993). "Tests for Parameter Instability and Structural Change with Unknown Change Point", Econometrica 61(4), 821-856.

[3] Barro, R. J. (1974). "Are Government Bonds Net Wealth?", Journal of Political Economy, 82(6),1095-1117.

[4] Barro, R. J. (1989). "The Ricardian Approach to Budget Deficits", Journal of Economic Perspectives 3(2), 37-54.

[5] Bernheim, B. D. (1987) "Ricardian Equivalence: An Evaluation of Theory and Evidence." NBER Macroeconomics, MIT Press: Cambridge, MA, 1988, 263304.

[6] Bryant, R. C., G. Holtham, and P. Hooper. (1988) "Consensus and Diversity in the Model Simulations," in Empirical Macroeconomics for Interdependent Economies, edited by R. C. Bryant, D. Henderson, G. Holtham, P. Hooper, and S. Symansky. Washington, D.C.: The Brookings Institute, 1988, 27-62.

[7] Corsetti, G. and Müller, G. J. (2006). "Twin deficits: squaring theory, evidence and commonsense", Economic Policy, 21(48), 597-638.

[8] Dibooglu, S. (1997) "Accounting for US Current Account Deficits: An Empirical Investigation", Applied Economics, 29, 1997, 787-93.

[9] Enders, W. and Lee, B (1990) "Current Account and Budget Deficits: Twins or Distant Cousins?", The Review of Economics and Statistics 72(3), 373-81.

[10] Engle, R. F and Granger, C. W.J.(1987). "Co-integration and Error Correction: Representation, Estimation, and Testing." Econometrica 55(2), 251-76.

[11] Gregory, A.W. and Hansen, B.E. (1996). "Residual-based tests of cointegration in models with regime shifts", Journal of Econometrics, 70, 99-126.

[12] Grier, K. and Ye, H. (2009) "Twin Sons of Different Mothers: The Long and the Short of The Twin Deficits Debate." Economic Inquiry, 47(4), 625-638. 
[13] Hansen, B. E. and Seo, B. (2002). "Testing for two-regime threshold cointegration in vector error-correction models." Journal of Econometrics, 110(2), $293-318$.

[14] Holmes M. J., Otero, J. and Panagiotidis, T. (2011). "Threshold cointegration and the short-run dynamics of twin deficit behaviour", Research in Economics $65(3), 271-277$.

[15] Holmes M. J., Otero, J. and Panagiotidis, T.(2010a) "Are EU Budget Deficits Sustainable?", Empirical Economics, 38(3), 767-778.

[16] Holmes M. J., Otero, J. and Panagiotidis, T.(2010b) "On the Stationarity of Current Account Deficits in the European Union", Review of International Economics, 18(4), 730-740.

[17] Holmes, M. J and Panagiotidis, T. (2009). "Cointegration and Asymmetric Adjustment: Some New Evidence Concerning the Behavior of the U.S. Current Account." The B.E. Journal of Macroeconomics 9(1), 23.

[18] Kim, Soyoung \& Nouriel Roubini. 2008. "Twin deficit or twin divergence? Fiscal policy, current account, and real exchange rate in the U.S." Journal of International Economics 74(2):362-383.

[19] Milne, E. (1977) "The Fiscal Approach to the Balance of Payments." Economic Notes, 89-107.

[20] Muller, G. J..(2008). "Understanding the Dynamic Effects of Government Spending on Foreign Trade", Journal of International Money and Finance, 27, $345-71$.

[21] Neaime, S. (2015) "Sustainability of budget deficits and public debts in selected European Union countries", The Journal of Economic Asymmetries, 12:1, 1-21.

[22] Pragidis, I., Gogas, P., Plakandaras, V., and Papadimitriou, T. (2015) "Fiscal shocks and asymmetric effects: A comparative analysis", The Journal of Economic Asymmetries, 12:1, 22-33. 
Table 1: Unit Root Tests

\begin{tabular}{lllll|llll}
\hline Country & $\mathrm{ADF}$ & & & & $\mathrm{PP}$ & & \\
\hline & $F D$ & $\Delta F D$ & $C A B$ & $\Delta C A B$ & $F D$ & $\Delta F D$ & $C A B$ & $\Delta C A B$ \\
\hline Botswana & -1.80 & $-3.61^{*}$ & -3.16 & -3.38 & -1.70 & $-5.08^{* *}$ & -2.00 & $-7.87^{* *}$ \\
Cameroon & -3.17 & $-5.01^{* *}$ & -3.36 & $-3.43^{*}$ & -2.91 & $-8.88^{* *}$ & -2.51 & $-8.75^{* *}$ \\
Egypt & -0.62 & $-6.15^{* *}$ & -2.63 & -2.24 & -2.90 & $-6.71^{* *}$ & -3.04 & $-5.05^{* *}$ \\
Ethiopia & -2.63 & $-4.09^{* *}$ & -2.54 & -3.07 & -2.48 & $-5.34^{* *}$ & -2.88 & $-5.60^{* *}$ \\
Ghana & $-5.87^{* *}$ & $-5.63^{* *}$ & $-3.79^{*}$ & $-4.97^{* *}$ & -2.78 & $-5.97^{* *}$ & $-4.18^{* *}$ & $-4.84^{* *}$ \\
Kenya & -2.55 & $-3.80^{*}$ & -2.47 & -2.64 & -2.32 & $-3.89^{*}$ & -2.56 & $-5.43^{* *}$ \\
Morocco & -2.09 & $-3.83^{*}$ & -2.37 & -2.99 & -2.12 & $-4.57^{* *}$ & -1.88 & $-4.85^{* *}$ \\
Nigeria & -3.34 & $-4.36^{* *}$ & -2.42 & $-5.58^{* *}$ & -2.66 & $-4.39^{* *}$ & -2.82 & $-4.76^{* *}$ \\
South Africa & -2.34 & $-4.08^{* *}$ & -3.03 & $-16.06^{* *}$ & -2.3 & $-4.02^{* *}$ & $-6.12^{* *}$ & $-16.43^{* *}$ \\
Tanzania & -1.66 & $-4.13^{* *}$ & -2.43 & $-3.87^{*}$ & -2.56 & $-4.56^{* *}$ & -2.05 & $-4.94^{* *}$ \\
Tunisia & $-4.06^{* *}$ & $-5.31^{* *}$ & $-3.75^{*}$ & -3.16 & $-4.45^{* *}$ & $-6.29^{* *}$ & -2.67 & $-5.09^{* *}$ \\
Uganda & -2.75 & $-4.12^{* *}$ & -2.61 & $-3.43^{*}$ & -1.99 & $-6.35^{* *}$ & -3.39 & $-4.69^{* *}$ \\
\hline
\end{tabular}

Note: Note: ${ }^{*}$ and ${ }^{* *}$ denote significant at 5 and 1 per cent levels respectively. 
Table 2: Tests for Threshold Cointegration

\begin{tabular}{ccccc}
\hline Country & $\begin{array}{c}\text { supLM } \\
\text { value }\end{array}$ & $\begin{array}{l}\text { Bootstrap } \\
p-\text { value }\end{array}$ & $\begin{array}{c}\text { Threshold } \\
\text { Parameter }(\gamma)\end{array}$ & $\begin{array}{c}\text { Cointegrating } \\
\text { vector }(\hat{\beta})\end{array}$ \\
\hline Botswana & $21.27^{* * *}$ & 0.01 & 5.95 & 0.37 \\
Cameroon & $23.46^{* * *}$ & 0.01 & -6.49 & 0.22 \\
Egypt & $16.38^{*}$ & 0.08 & 6.50 & 0.99 \\
Ethiopia & $15.81^{*}$ & 0.09 & -38.78 & -5.00 \\
Kenya & $18.25^{* *}$ & 0.02 & -13.62 & -6.64 \\
Morocco & $19.19^{*}$ & 0.09 & -6.55 & 3.04 \\
Nigeria & $18.60^{* * *}$ & 0.01 & -53.26 & 2.97 \\
Tanzania & $21.83^{* * *}$ & 0.01 & 24.49 & 7.07 \\
Uganda & $19.84^{* * *}$ & 0.01 & -14.38 & -4.07 \\
\hline
\end{tabular}

Note:The $p$-value for the sup LM test are obtained from a parametric residual bootstrap with 5000 replications. For both sup LM and $\hat{\beta}$, the value of $\gamma$ is derived from a grid search procedure where the significance of $\gamma$ is addressed through the sup LM test which rejects the null of cointegration with no threshold in favour of the alternative of cointegration with a threshold.

$*, * *$, and ${ }^{* * *}$ denotes significance at the 10, 5 and 1 per cent significance level respectively. Nine countries were examined because the fiscal deficits and the current account deficits variables were integrated of order one, and it is a condition for cointegration analysis. The results were generated using the GAUSS software. The codes were obtained from Hansen's web page for the Hansen and Seo (2002) threshold cointegration. 
Table 3: Botswana and Cameroon Threshold VECM

\begin{tabular}{|c|c|c|c|c|}
\hline Botswana & $1^{s t}$ Regime & $\left(\hat{\omega}_{t-1} \geq 5.95\right)$ & $2^{\text {nd }}$ Regime & $\left(\hat{\omega}_{t-1}<5.95\right)$ \\
\hline Variables & CAB Model & FD Model & CAB Model & FD Model \\
\hline \multirow[t]{2}{*}{ Intercept } & $0.917^{* *}$ & 0.215 & $3.769^{* *}$ & $-1.413^{* *}$ \\
\hline & $(0.359)$ & $(0.138)$ & $(1.767)$ & $(0.562)$ \\
\hline \multirow[t]{2}{*}{$\hat{\omega}_{t-1}$} & -0.033 & 0.004 & $-0.516^{* * *}$ & $0.097^{* *}$ \\
\hline & $(0.036)$ & $(0.009)$ & $(0.179)$ & $(0.041)$ \\
\hline \multirow[t]{2}{*}{$\Delta \mathrm{cab}_{t-1}$} & $0.326^{* * *}$ & $0.067^{* *}$ & $0.555^{* * *}$ & 0.019 \\
\hline & $(0.074)$ & $(0.027)$ & $(0.156)$ & $(0.040)$ \\
\hline \multirow[t]{2}{*}{$\Delta \mathrm{cab}_{t-2}$} & 0.100 & $0.560^{* * *}$ & -0.178 & $0.525^{* * *}$ \\
\hline & $(0.166)$ & $(0.156)$ & $(0.145)$ & $(0.141)$ \\
\hline \multirow[t]{2}{*}{$\Delta \mathrm{fd}_{t-1}$} & 0.077 & $0.051^{* *}$ & $0.496^{* * *}$ & -0.028 \\
\hline & $(0.052)$ & $(0.025)$ & $(0.174)$ & $(0.045)$ \\
\hline \multirow[t]{2}{*}{$\Delta \mathrm{fd}_{t-2}$} & 0.122 & 0.125 & 0.102 & 0.087 \\
\hline & $(0.157)$ & $(0.097)$ & $(0.147)$ & $(0.071)$ \\
\hline$\%$ of Observation & \multicolumn{2}{|c|}{59} & \multicolumn{2}{|c|}{41} \\
\hline Cameroon & $\mathrm{I}^{s t}$ Regime & $\left(\hat{\omega}_{t-1} \leq-6.49\right)$ & $2^{\text {nd }}$ Regime & $\left(\hat{\omega}_{t-1}>-6.49\right)$ \\
\hline Variables & CAB Model & FD Model & CAB Model & FD Model \\
\hline \multirow[t]{2}{*}{ Intercept } & $2.046^{* * *}$ & $25.992^{* *}$ & $-0.458^{* * *}$ & 0.171 \\
\hline & $(0.685)$ & $(10.037)$ & $(0.125)$ & $(0.150)$ \\
\hline \multirow[t]{2}{*}{$\hat{\omega}_{t-1}$} & $0.201^{* *}$ & $3.445^{* * *}$ & $-0.101^{* *}$ & 0.039 \\
\hline & $(0.084)$ & $(1.307)$ & $(0.044)$ & $(0.051)$ \\
\hline \multirow[t]{2}{*}{$\Delta \mathrm{cab}_{t-1}$} & $0.403^{* * *}$ & 0.457 & $0.475^{* * *}$ & -0.053 \\
\hline & $(0.109)$ & $(0.643)$ & $(0.102)$ & $(0.087)$ \\
\hline \multirow[t]{2}{*}{$\Delta \mathrm{cab}_{t-2}$} & 0.004 & $0.493^{* * *}$ & -0.053 & 0.421 \\
\hline & $(0.006)$ & $(0.157)$ & $(0.041)$ & $(0.297)$ \\
\hline \multirow[t]{2}{*}{$\Delta \mathrm{fd}_{t-1}$} & 0.087 & -0.375 & $0.127^{* *}$ & -0.042 \\
\hline & $(0.064)$ & $(0.627)$ & $(0.058)$ & $(0.050)$ \\
\hline \multirow[t]{2}{*}{$\Delta \mathrm{fd}_{t-2}$} & 0.016 & $0.685^{* *}$ & -0.023 & 0.039 \\
\hline & $(0.018)$ & $(0.305)$ & $(0.019)$ & $(0.098)$ \\
\hline$\%$ of Observation & & & & \\
\hline
\end{tabular}

Notes: Notes: Eicker-White standard errors given in parentheses. The selection of a lag length of 2 in the threshold VECM is based on the use of the SIC applied to an unrestricted VAR comprising the CAB and FD *, ${ }^{* *}$, and ${ }^{* * *}$ denotes significance at the 10, 5 and 1 per cent significance level respectively. 
Table 4: Egypt and Ethiopia Threshold VECM

\begin{tabular}{|c|c|c|c|c|}
\hline Egypt & $1^{s t}$ Regime & $\left(\hat{\omega}_{t-1} \geq 6.50\right)$ & $2^{\text {nd }}$ Regime & $\left(\hat{\omega}_{t-1}<6.50\right)$ \\
\hline Variables & CAB Model & FD Model & CAB Model & FD Model \\
\hline \multirow[t]{2}{*}{ Intercept } & 0.086 & $-0.319 * * *$ & $1.169^{*}$ & 1.948 \\
\hline & $(0.061)$ & $(0.109)$ & $(0.638)$ & $(1.692)$ \\
\hline \multirow[t]{2}{*}{$\hat{\omega}_{t-1}$} & -0.008 & -0.015 & $-0.128^{* *}$ & -0.044 \\
\hline & $(0.013)$ & $(0.022)$ & $(0.056)$ & $(0.130)$ \\
\hline \multirow[t]{2}{*}{$\Delta \mathrm{cab}_{t-1}$} & $0.777^{* * *}$ & -0.203 & $0.434^{* * *}$ & $0.826^{* * *}$ \\
\hline & $(0.161)$ & $(0.213)$ & $(0.160)$ & $(0.293)$ \\
\hline \multirow[t]{2}{*}{$\Delta \mathrm{cab}_{t-2}$} & -0.014 & $0.364^{* * *}$ & 0.107 & $1.242 * * *$ \\
\hline & $(0.029)$ & $(0.091)$ & $(0.104)$ & $(0.299)$ \\
\hline \multirow[t]{2}{*}{$\Delta \mathrm{fd}_{t-1}$} & 0.048 & 0.017 & 0.071 & $-0.648^{* *}$ \\
\hline & $(0.069)$ & $(0.102)$ & $(0.117)$ & $(0.312)$ \\
\hline \multirow[t]{2}{*}{$\Delta \mathrm{fd}_{t-2}$} & 0.032 & $0.185^{* *}$ & -0.038 & -0.061 \\
\hline & $(0.021)$ & $(0.076)$ & $(0.104)$ & $(0.211)$ \\
\hline$\%$ of Observation & \multicolumn{2}{|c|}{78} & \multicolumn{2}{|c|}{22} \\
\hline Ethiopia & $\mathrm{I}^{s t}$ Regime & $\left(\hat{\omega}_{t-1} \leq-38.78\right)$ & $2^{\text {nd }}$ Regime & $\left(\hat{\omega}_{t-1}>-38.78\right)$ \\
\hline Variables & CAB Model & FD Model & CAB Model & FD Model \\
\hline \multirow[t]{2}{*}{ Intercept } & $-16.892^{* * *}$ & $9.945^{* * *}$ & $-0.399^{*}$ & $-0.549^{* * *}$ \\
\hline & $(6.342)$ & $(1.462)$ & $(0.213)$ & $(0.152)$ \\
\hline \multirow[t]{2}{*}{$\hat{\omega}_{t-1}$} & $-0.388^{* *}$ & $0.204^{* * *}$ & -0.017 & $-0.021^{* * *}$ \\
\hline & $(0.151)$ & $(0.033)$ & $(0.011)$ & $(0.006)$ \\
\hline \multirow{2}{*}{$\Delta \mathrm{cab}_{t-1}$} & -0.093 & $0.154^{* * *}$ & $0.477^{* * *}$ & 0.039 \\
\hline & $(0.210)$ & $(0.058)$ & $(0.114)$ & $(0.046)$ \\
\hline \multirow[t]{2}{*}{$\Delta \mathrm{cab}_{t-2}$} & -0.527 & $0.823^{* * *}$ & 0.108 & $0.466^{* * *}$ \\
\hline & $(0.224)$ & $(0.106)$ & $(0.090)$ & $(0.088)$ \\
\hline \multirow[t]{2}{*}{$\Delta \mathrm{fd}_{t-1}$} & -0.043 & -0.058 & 0.081 & $0.067^{*}$ \\
\hline & $(0.165)$ & $(0.047)$ & $(0.063)$ & $(0.036)$ \\
\hline \multirow{2}{*}{$\Delta \mathrm{fd}_{t-2}$} & -0.096 & $0.375^{* * *}$ & 0.066 & $0.188^{* * *}$ \\
\hline & $(0.296)$ & $(0.092)$ & $(0.071)$ & $(0.063)$ \\
\hline$\%$ of Observation & & & & \\
\hline
\end{tabular}

Notes: Notes: Eicker-White standard errors given in parentheses. The selection of a lag length of 2 in the threshold VECM is based on the use of the SIC applied to an unrestricted VAR comprising the CAB and FD *, **, and *** denotes significance at the 10, 5 and 1 per cent significance level respectively. 
Table 5: Kenya and Morocco Threshold VECM

\begin{tabular}{|c|c|c|c|c|}
\hline $\begin{array}{c}\text { Kenya } \\
\text { Variables }\end{array}$ & $\begin{array}{l}1^{\text {st }} \text { Regime } \\
\text { CAB Model }\end{array}$ & $\begin{array}{l}\left(\hat{\omega}_{t-1} \leq-13.62\right) \\
\text { FD Model }\end{array}$ & $\begin{array}{l}2^{n d} \text { Regime } \\
\text { CAB Model }\end{array}$ & $\begin{array}{l}\left(\hat{\omega}_{t-1}>-13.62\right) \\
\text { FD Model }\end{array}$ \\
\hline \multirow{2}{*}{ Intercept } & 5.789 & 2.659 & -0.188 & -0.027 \\
\hline & $(3.771)$ & $(1.647)$ & $(0.226)$ & $(0.097)$ \\
\hline \multirow[t]{2}{*}{$\hat{\omega}_{t-1}$} & 0.265 & $0.153^{*}$ & 0.012 & -0.002 \\
\hline & $(0.218)$ & $(0.093)$ & $(0.037)$ & $(0.013)$ \\
\hline \multirow[t]{2}{*}{$\Delta \mathrm{cab}_{t-1}$} & $0.785^{* * *}$ & 0.001 & $0.341^{* * *}$ & -0.004 \\
\hline & $(0.250)$ & $(0.121)$ & $(0.071)$ & $(0.022)$ \\
\hline \multirow[t]{2}{*}{$\Delta \mathrm{cab}_{t-2}$} & 0.276 & $0.765^{*}$ & -0.273 & $0.589^{* * *}$ \\
\hline & $(0.575)$ & $(0.387)$ & $(0.202)$ & $(0.122)$ \\
\hline \multirow[t]{2}{*}{$\Delta \mathrm{fd}_{t-1}$} & $0.805^{* * *}$ & -0.081 & 0.049 & 0.002 \\
\hline & $(0.257)$ & $(0.099)$ & $(0.047)$ & $(0.013)$ \\
\hline \multirow[t]{2}{*}{$\Delta \mathrm{fd}_{t-2}$} & $1.931^{* * *}$ & -0.213 & $-0.440^{*}$ & $0.257^{* *}$ \\
\hline & $(0.668)$ & $(0.274)$ & $(0.244)$ & $(0.100)$ \\
\hline$\%$ of Observation & \multicolumn{2}{|c|}{16} & \multicolumn{2}{|c|}{84} \\
\hline Morocco & $1^{\text {st }}$ Regime & $\left(\hat{\omega}_{t-1} \leq-6.55\right)$ & $2^{\text {nd }}$ Regime & $\left(\hat{\omega}_{t-1}>-6.55\right)$ \\
\hline Variables & CAB Model & FD Model & CAB Model & FD Model \\
\hline \multirow[t]{2}{*}{ Intercept } & -2.588 & $3.018^{*}$ & 0.022 & -0.079 \\
\hline & $(2.251)$ & $(1.551)$ & $(0.075)$ & $(0.065)$ \\
\hline \multirow[t]{2}{*}{$\hat{\omega}_{t-1}$} & -0.231 & $0.382^{* *}$ & 0.004 & $0.015^{* * *}$ \\
\hline & $(0.213)$ & $(0.151)$ & $(0.006)$ & $(0.004)$ \\
\hline \multirow[t]{2}{*}{$\Delta \mathrm{cab}_{t-1}$} & $0.439^{*}$ & -0.037 & $0.538^{* * *}$ & -0.048 \\
\hline & $(0.239)$ & $(0.114)$ & $(0.114)$ & $(0.061)$ \\
\hline \multirow[t]{2}{*}{$\Delta \mathrm{cab}_{t-2}$} & -0.002 & $1.013^{* * *}$ & -0.134 & $0.529^{* * *}$ \\
\hline & $(0.255)$ & $(0.341)$ & $(0.098)$ & $(0.097)$ \\
\hline \multirow[t]{2}{*}{$\Delta \mathrm{fd}_{t-1}$} & 0.102 & $-0.332^{*}$ & 0.097 & -0.007 \\
\hline & $(0.157)$ & $(0.197)$ & $(0.066)$ & $(0.046)$ \\
\hline \multirow[t]{2}{*}{$\Delta \mathrm{fd}_{t-2}$} & -0.275 & $0.778^{* *}$ & -0.071 & $0.154^{* * *}$ \\
\hline & $(0.320)$ & $(0.317)$ & $(0.088)$ & $(0.066)$ \\
\hline$\%$ of Observation & & & & \\
\hline
\end{tabular}

Notes: Notes: Eicker-White standard errors given in parentheses. The selection of a lag length of 2 in the threshold VECM is based on the use of the SIC applied to an unrestricted VAR comprising the CAB and FD *, **, and *** denotes significance at the 10,5 and 1 per cent significance level respectively. 
Table 6: Nigeria and Tanzania Threshold VECM

\begin{tabular}{|c|c|c|c|c|}
\hline Nigeria & $1^{s t}$ Regime & $\left(\hat{\omega}_{t-1} \leq-53.26\right)$ & $2^{\text {nd }}$ Regime & $\left(\hat{\omega}_{t-1}>-53.26\right)$ \\
\hline Variables & CAB Model & FD Model & CAB Model & FD Model \\
\hline \multirow{2}{*}{ Intercept } & $-11.253^{* * *}$ & $9.164^{*}$ & $0.703^{* *}$ & $1.555^{* *}$ \\
\hline & (2.709) & $(5.31)$ & $(0.297)$ & $(0.593)$ \\
\hline \multirow{2}{*}{$\hat{\omega}_{t-1}$} & $-0.151^{* * *}$ & $0.142^{* *}$ & $0.027^{* *}$ & $0.066^{* * *}$ \\
\hline & $(0.041)$ & $(0.069)$ & $(0.012)$ & $(0.020)$ \\
\hline \multirow[t]{2}{*}{$\Delta \mathrm{cab}_{t-1}$} & $0.171^{* *}$ & 0.568 & $0.572^{* * *}$ & 0.009 \\
\hline & $(0.084)$ & $(0.369)$ & $(0.138)$ & $(0.118)$ \\
\hline \multirow[t]{2}{*}{$\Delta \mathrm{cab}_{t-2}$} & -0.140 & $0.895^{* *}$ & -0.011 & $0.549^{* * *}$ \\
\hline & $(0.077)$ & $(0.379)$ & $(0.071)$ & $(0.144)$ \\
\hline \multirow{2}{*}{$\Delta \mathrm{fd}_{t-1}$} & $0.189^{* *}$ & -0.171 & 0.143 & 0.058 \\
\hline & $(0.091)$ & $(0.218)$ & $(0.100)$ & $(0.093)$ \\
\hline \multirow[t]{2}{*}{$\Delta \mathrm{fd}_{t-2}$} & -0.058 & 0.129 & 0.028 & $0.166^{*}$ \\
\hline & $(0.086)$ & $(0.156)$ & $(0.056)$ & $(0.092)$ \\
\hline$\%$ of Observation & \multicolumn{2}{|c|}{16} & \multicolumn{2}{|c|}{84} \\
\hline Tanzania & $1^{\text {st }}$ Regime & $\left(\hat{\omega}_{t-1} \geq 24.49\right)$ & $2^{\text {nd }}$ Regime & $\left(\hat{\omega}_{t-1}<24.49\right)$ \\
\hline Variables & CAB Model & FD Model & CAB Model & FD Model \\
\hline \multirow[t]{2}{*}{ Intercept } & 0.124 & $-0.155^{* *}$ & $-4.726^{* * *}$ & -1.783 \\
\hline & $(0.096)$ & $(0.078)$ & $(1.668)$ & (1.336) \\
\hline \multirow[t]{2}{*}{$\hat{\omega}_{t-1}$} & $-0.014^{* *}$ & $0.018^{* * *}$ & $0.138^{* * *}$ & $0.070^{*}$ \\
\hline & $(0.006)$ & $(0.006)$ & $(0.045)$ & $(0.037)$ \\
\hline \multirow[t]{2}{*}{$\Delta \mathrm{cab}_{t-1}$} & $0.469^{* * *}$ & 0.009 & $1.258^{* * *}$ & -0.902 \\
\hline & $(0.089)$ & $(0.054)$ & $(0.276)$ & $(0.340)$ \\
\hline \multirow[t]{2}{*}{$\Delta \mathrm{cab}_{t-2}$} & 0.107 & $0.431^{* * *}$ & -0.205 & $1.392^{* * *}$ \\
\hline & $(0.097)$ & $(0.105)$ & $(0.227)$ & $(0.333)$ \\
\hline \multirow[t]{2}{*}{$\Delta \mathrm{fd}_{t-1}$} & 0.065 & -0.003 & $0.791^{* *}$ & 0.329 \\
\hline & $(0.064)$ & $(0.039)$ & $(0.350)$ & $(0.293)$ \\
\hline \multirow{2}{*}{$\Delta \mathrm{fd}_{t-2}$} & -0.032 & $0.177^{* *}$ & 0.151 & 0.049 \\
\hline & $(0.079)$ & $(0.084)$ & $(0.125)$ & $(0.119)$ \\
\hline$\%$ of Observation & 9 & & & \\
\hline
\end{tabular}

Notes: Notes: Eicker-White standard errors given in parentheses. The selection of a lag length of 2 in the threshold VECM is based on the use of the SIC applied to an unrestricted VAR comprising the CAB and FD *, **, and ${ }^{* * *}$ denotes significance at the 10,5 and 1 per cent significance level respectively. 
Table 7: Uganda Threshold VECM

\begin{tabular}{ccccc} 
Uganda & $1^{\text {st }}$ Regime & $\left(\hat{\omega}_{t-1} \leq-14.38\right)$ & $2^{n d}$ Regime & $\left(\hat{\omega}_{t-1}>-14.38\right)$ \\
Variables & CAB Model & FD Model & CAB Model & FD Model \\
\hline Intercept & 0.439 & $-1.538^{* * *}$ & -0.111 & -0.058 \\
& $(0.704)$ & $(0.464)$ & $(0.074)$ & $(0.042)$ \\
$\hat{\omega}_{t-1}$ & 0.056 & $-0.118^{* * *}$ & $-0.033^{* * *}$ & -0.010 \\
& $(0.042)$ & $(0.027)$ & $(0.013)$ & $(0.007)$ \\
$\Delta \mathrm{cab}_{t-1}$ & 0.031 & 0.015 & $0.526^{* * *}$ & 0.034 \\
& $(0.114)$ & $(0.125)$ & $(0.123)$ & $(0.046)$ \\
$\Delta \mathrm{cab}_{t-2}$ & -0.816 & $0.684^{* * *}$ & 0.063 & $0.382^{* * *}$ \\
$\Delta \mathrm{fd}_{t-1}$ & $(0.179)$ & $(0.197)$ & $(0.148)$ & $0.102)$ \\
$\Delta \mathrm{fd}_{t-2}$ & -0.267 & 0.005 & $0.178^{* *}$ & 0.005 \\
$\%$ of & $(0.112)$ & $(0.124)$ & $(0.077)$ & $0.032)$ \\
Observation & -1.046 & $0.479^{* *}$ & -0.026 & 0.075 \\
& $(0.208)$ & $(0.217)$ & $(0.087)$ & $(0.051)$ \\
\hline
\end{tabular}

Notes: Notes: Eicker-White standard errors given in parentheses. The selection of a lag length of 2 in the threshold VECM is based on the use of the SIC applied to an unrestricted VAR comprising the CAB and FD *, ${ }^{* *}$, and ${ }^{* * *}$ denotes significance at the 10,5 and 1 per cent significance level respectively. 


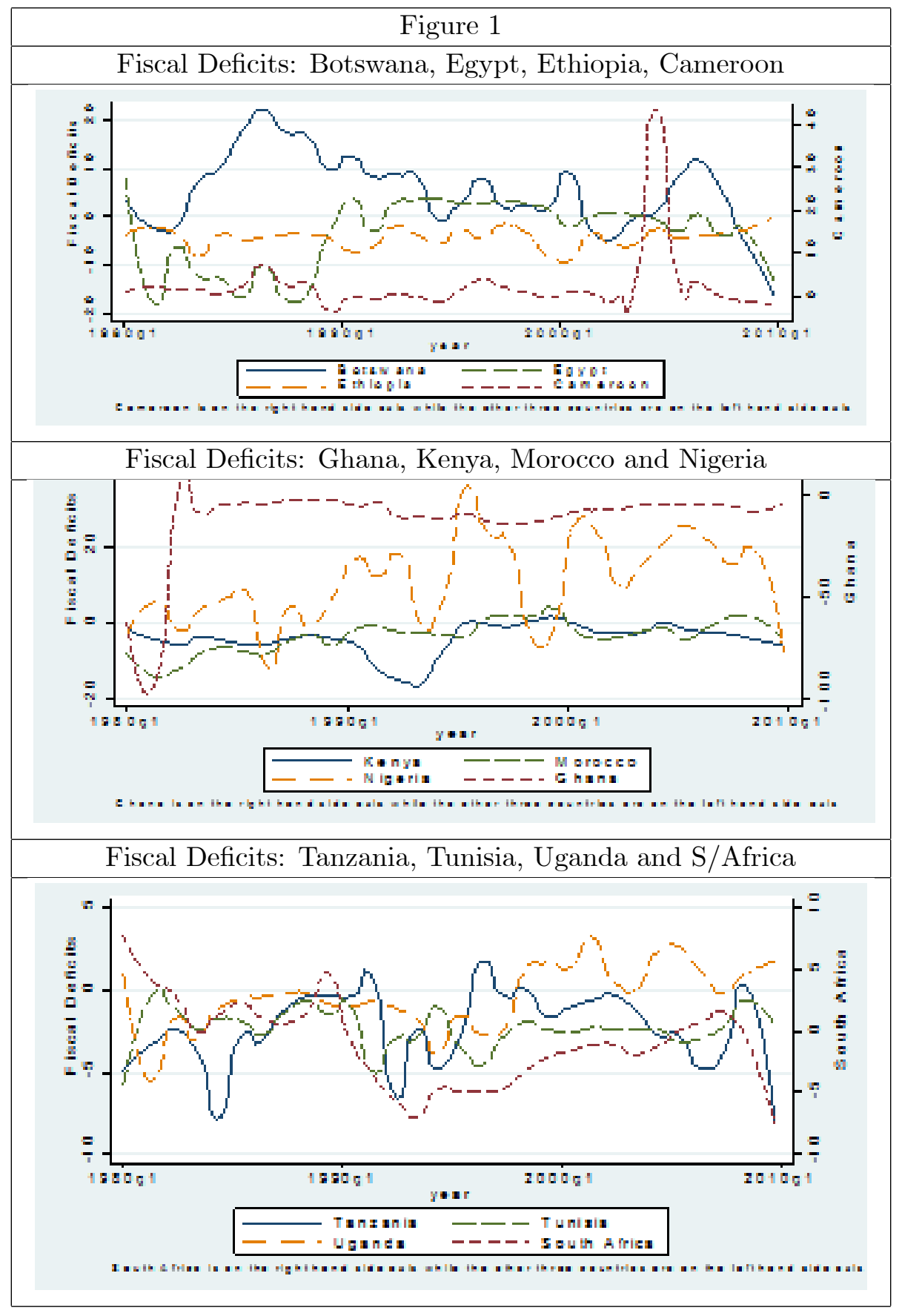




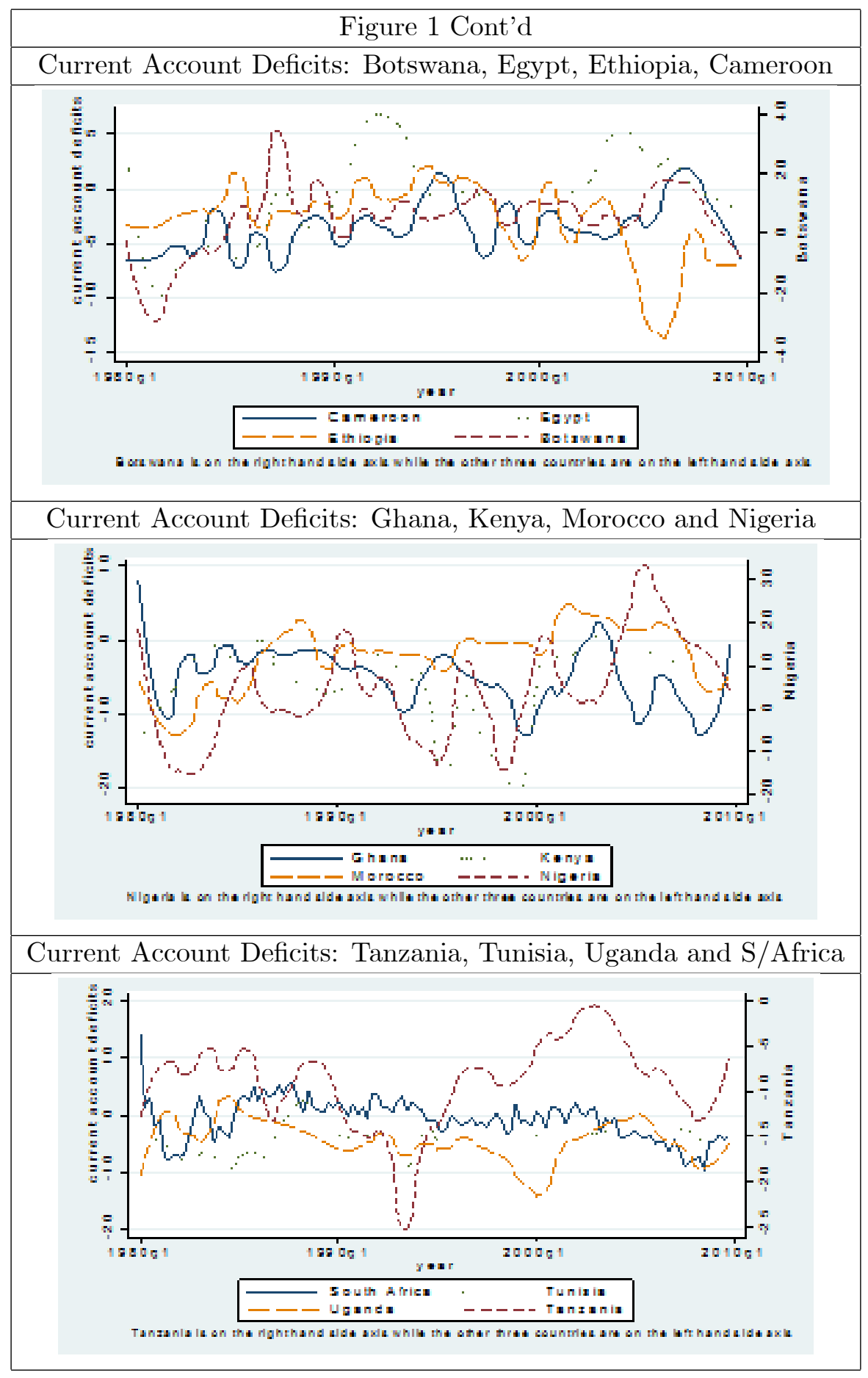




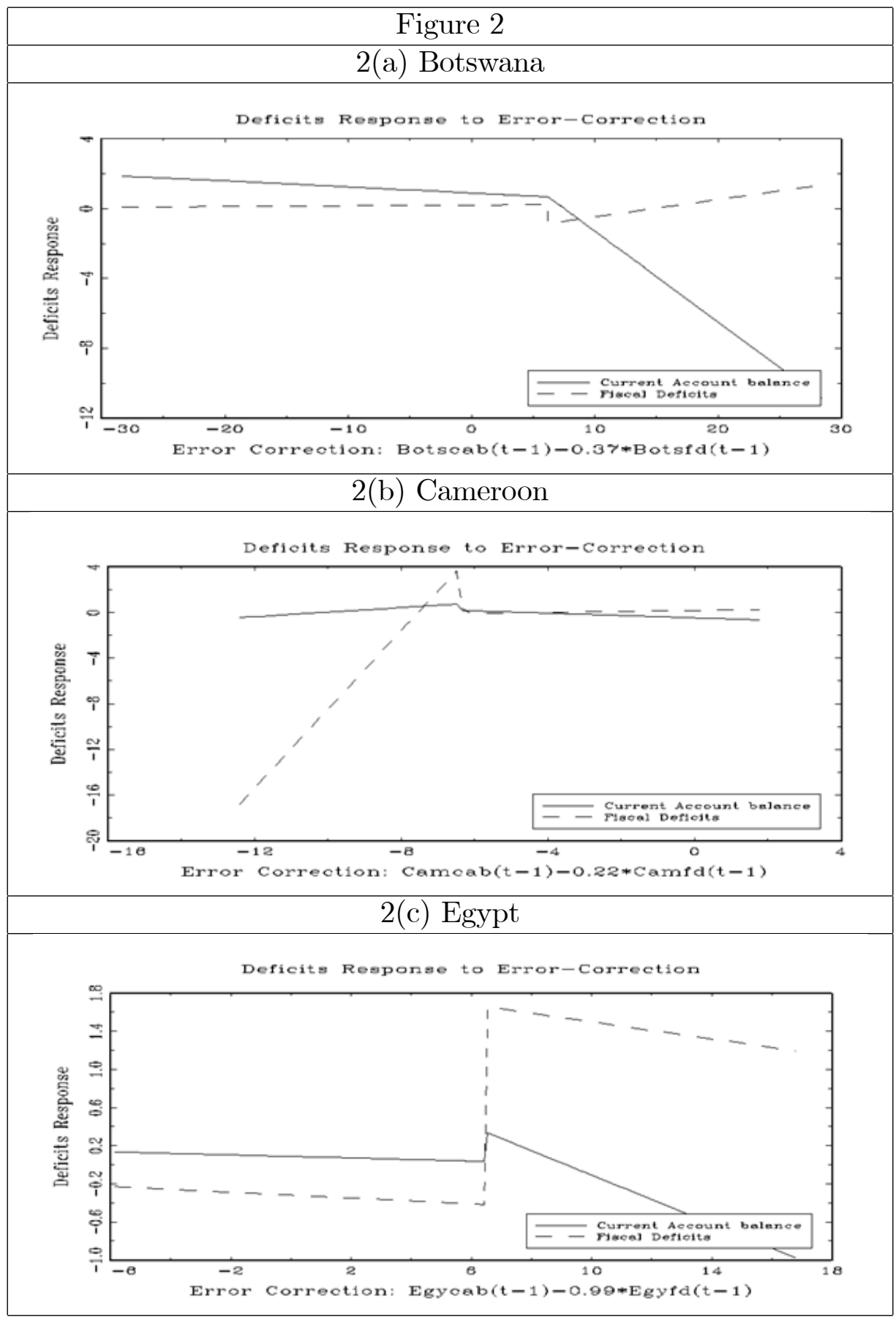




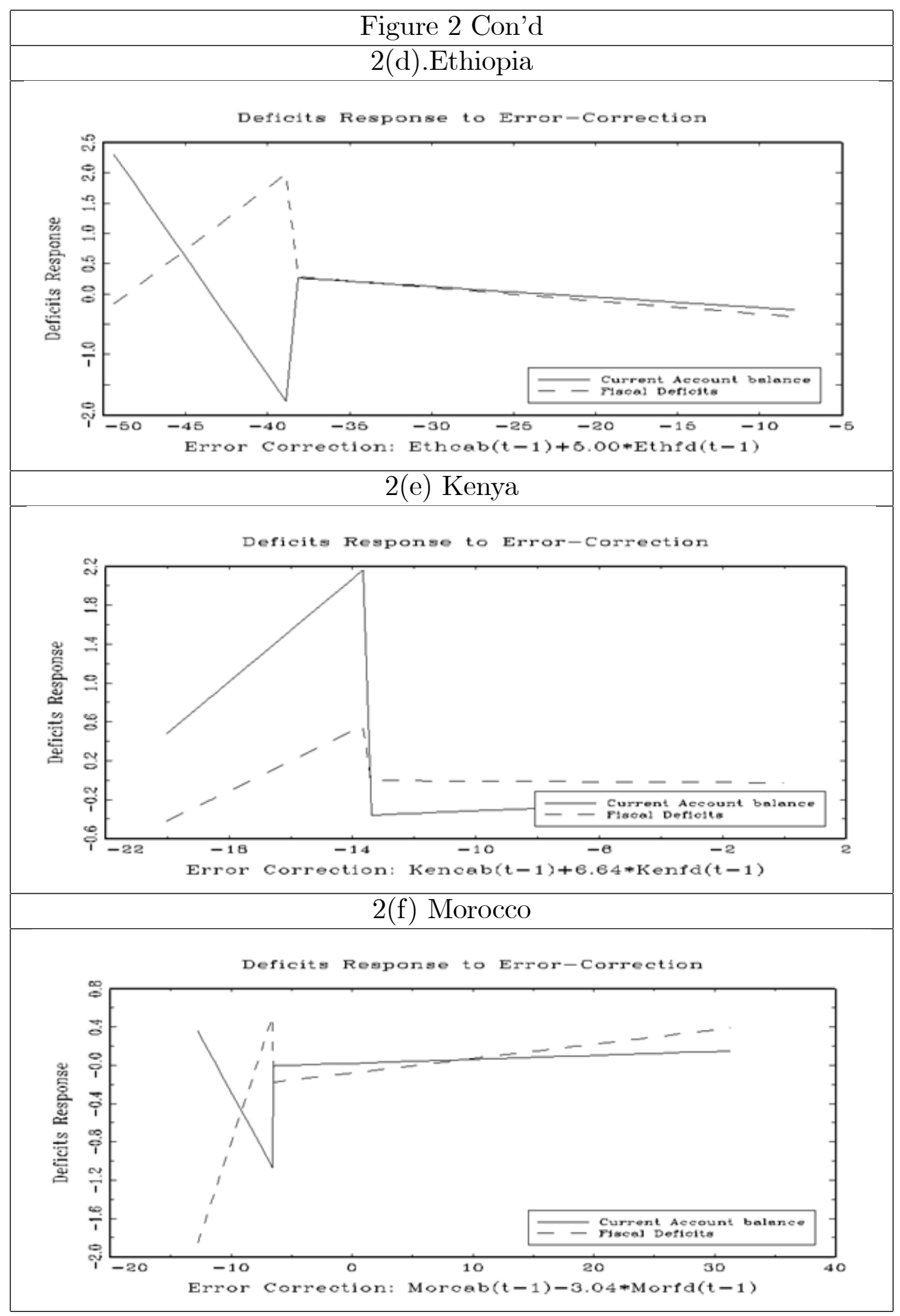




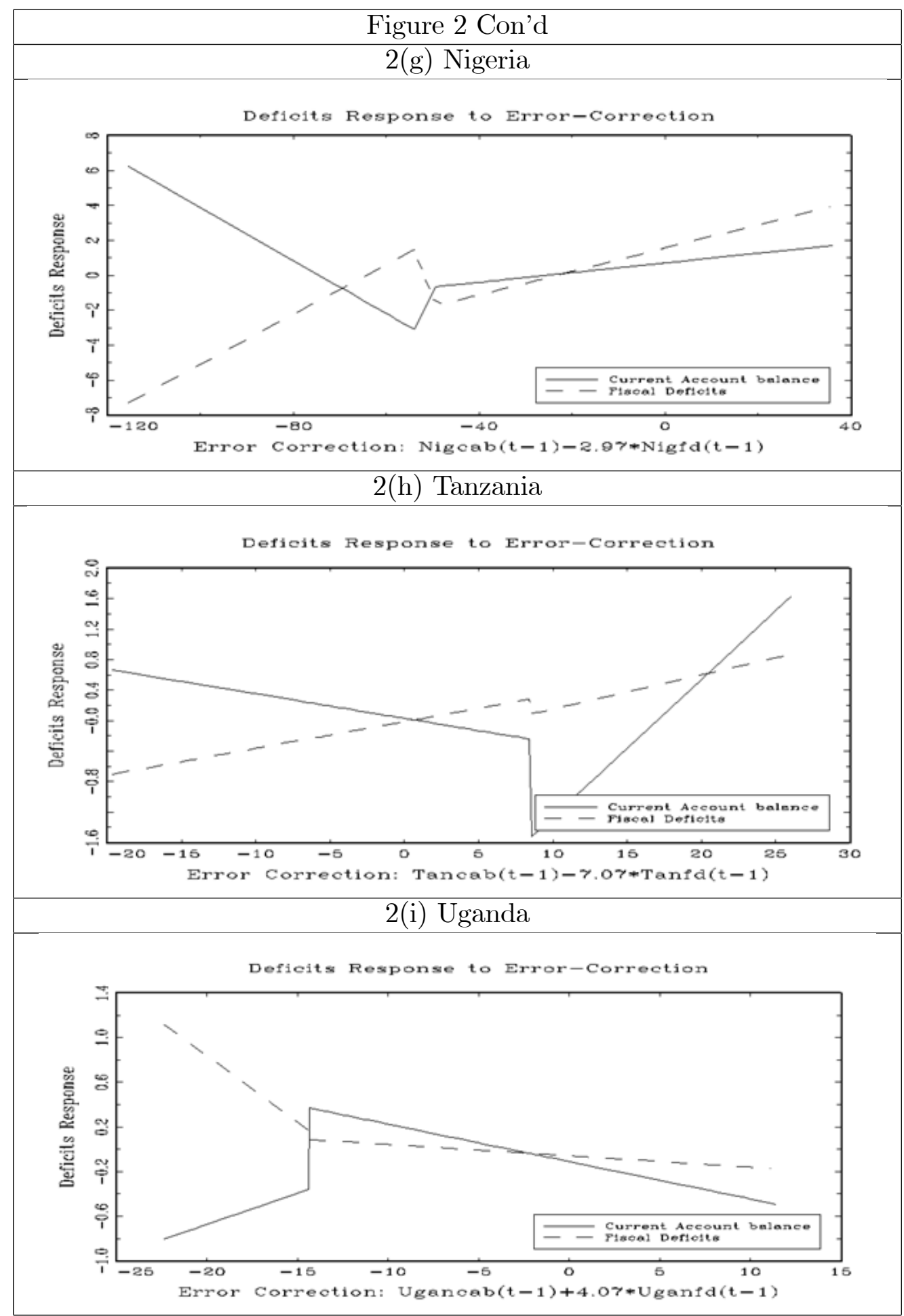

